\title{
Surrogate Marker
}

National Cancer Institute

\section{Source}

National Cancer Institute. Surrogate Marker. NCI Thesaurus. Code C142724.

In a clinical trial, an assessment of an intervention's effects that takes the place of a patient-based conclusion. 